\title{
Urban Farming Activities in Southeast Asia: A Review and Future Research Direction
}

\author{
Siti Aisyah Salim ${ }^{1 *}$, Musaab Alaa ${ }^{2}$, Zawiyah Mohammad Yusof ${ }^{3}$, Laili Farhana Md Ibharim ${ }^{4}$ Siti Hajar Salim ${ }^{5}$, and Fazian \\ Hashim $^{6}$ \\ ${ }^{1 *, 6}$ Faculty of Technology Management and Business, UTHM, Batu Pahat, Johor, Malaysia. \\ ${ }^{2,4}$ Universiti Pendidikan Sultan Idris, Tanjung Malim, Perak, Malaysia. \\ ${ }^{3}$ Universiti Kebangsaan Malaysia, Bangi, Selangor, Malaysia. \\ ${ }^{5}$ Cyberjaya University College of Medical Sciences, Bangi, Selangor, Malaysia.
}

\begin{abstract}
The activities of urban farming in Southeast are still limited and scattered. In order to give valuable insights into the urban agriculture of Southeast Asia and to support researchers, we need to know in details the available options and gaps in this research direction that will serve future researchers. Thus, in this study, a review is conducted to map the research landscape into a coherent taxonomy. The research procedure focuses on all these subject matters related to urban farming system activities, technology application and their use in the urban farms and smallholder farming activities in Southeast Asia. These studies selected from the three major digital databases, namely, the ScienceDirect, Web of Science, and Scopus. The study selection process consists of research into literature sources, followed by three iterations of screening and filtering, excluded duplicate articles, screening the titles and abstracts and reading of the full-text articles. The final included result is 88 articles, which will be adopted on in this study. Further, a review in details of the layout of the research landscape of literature is conducted into a cohesive classification with its descriptive analysis. We also identify the essential characteristics of this emerging field in the following aspects: benefits of using urban farming activities in Southeast Asia, challenges hindering utilization, and recommendations to improve the acceptance and use of urban farming applications in literature.
\end{abstract}

\section{Introduction}

Urban farming or urban agriculture refers to the farming activities in urban areas, which are commonly used for income or food. It contributes to food security, food safety, and improve the quality of the environment and greening the country, especially the urban area [1]. The urban agriculture program focuses on providing food security to people in urban areas and economic diversification. The program also supports the use of unproductive land and encourages the population to construct small farm gardens in homes by following spatial characteristics in each region. The creation of an agricultural community in each target city leads to increased environmental awareness [2].

Urban farming activities are essential in urban areas as they grow to meet the needs of a constantly evolving urban life. A variety of systems may fall under the concept of urban agriculture in a different range and possession, ranging from small community gardens [3], peri-urban farming [4], [5], small farming, urban gardens, the building of vertical farming or greenhouse [6]. These farms provide a part of the community with the self-sufficiency of the food system and food safety.
Urban farming has real potential for achieving more productive and sustainable agricultural production for urban areas. Intelligent agriculture is the application of modern information and communication technology within agricultural fields. These technologies can control agricultural fields, such as precision equipment, internet of things (IoT) [7], [8], [9], sensor devises [10], [11], geographic positioning systems (GPS) [12], data collection devices [13], robot devises [14] and etc. This technology contributes and helps many farmers to monitor the farms in a simplified and accurate way that causes the success of agriculture. Assessment devices utilised by measuring, agricultural crops, soil properties, organic substance content, moisture levels, nitrogen levels, etc. Thus, the current study aims to shed light on the efforts of researchers in response to new and disruptive technology and the research landscape from the literature into coherent taxonomy. It also determines the various features that characterize this emerging line of research in urban farming activities, technology applications and their use in urban farms and smallholder farming activities in Southeast in various topics. The remainder of this paper organised as follows: In section 1 , presents the introduction of urban farming activities in

Corresponding author: author@e-mail.org 
Southeast Asia. In section 2, presents research methods steps, research scope, literature sources and steps of the filtering process. In Section 3, the paper will provide results and statistical information of the included articles. In section 4, it presents benefits, challenges, and recommendations. Section 5 and 6 , presents the limitation and conclusion of the review paper.

\section{Research method}

The keyword in the scope of this paper is "Quality of Life through Urban Farming Activities in Southeast Asia." It excludes any Urban Farming Activities not related to Southeast Asia such as those found in China, Japan, Taiwan, Korea, and other countries. We also limit our scope to the English literature, but consider all studies in exploring determinants towards enhancing the quality of life through urban farming activities in Southeast Asia. Three digital databases were explored to search the target articles. Web of Science database cover services indexing cross-disciplinary research in agriculture, engineering, medical and life sciences, biological sciences, physical and chemical sciences. ScienceDirect and Scopus is the largest scholarly research database that provides the most reliable and wide range of topics such as, monitoring system, IoT applications, urban farming support livelihood, food, and few more related topics. These three databases sufficiently cover the agriculture studies, especially topic the urban farming activities in Southeast Asia.

Study selection involved a search for literature sources, followed by three iterations of screening and filtering. The first iteration process excluded the duplicate papers between databases. The second iteration process screening the titles and abstracts papers and excluded separate articles, while another iteration of items after a thorough reading of the full-text articles examined by the second candidate. The search was conducted in November 2017 using the search boxes of ScienceDirect, WoS database and SCOPUS. We used a mix of keywords that contained "smart farming", "home farming", "town farming", "city farming", "homegrown farming", "home-grown farming", "home-based farming", "Precision Livestock Farming", PLF, "urban farming") on different variation and combined with the "OR" and "AND" operators followed by Southeast Asia countries (Malaysia OR Brunei OR Cambodia OR Indonesia OR Laos OR Myanmar OR Philippines OR Singapore OR Thailand OR Vietnam OR "Southeast Asia"). The exact query text is shown in Figure 1 below. The advanced search options in the search engines were used to exclude book chapters, short communication, correspondence, and letter and gain access to current scientific works relevant to urban farming activities in Southeast Asia. We analyse the final articles by using Microsoft words and Excel formats. Notably, the final set of articles was categorized in detail using taxonomy. This taxonomy is classified into several classes and subclasses. The text is categorised according to the preferred author style, and the collected data and related information are saved in Word and Excel files. All articles are analysed from a variety of sources in depth to give readers a comprehensive look at the subject.

\section{Result and statistical information of articles}

The initial query resulted in 851 papers: 17 from the Web of Science database, 378 from ScienceDirect, and 456 from Scopus. The filtered articles published until 2017 were adopted in this research and divided into three categories. In the three databases the included papers are filtering in three parts; the first part, 2 out papers were duplicates from the total number 851 , the second part, after reading the titles and abstract, 761 excluded from the number of 849 , the result becomes 130 , in the second parts of the filtering process 42 papers were excluded, from the number of 130 the final included papers 88 eighty-eight.

\section{Query:}

("smart farming" OR "home farming" OR "town farming" OR "city farming" OR "homegrown farming" OR "home-grown farming" OR "home-based farming" OR "Precision Livestock Farming" OR PLF OR "urban farming") AND (Malaysia OR Brunei OR Cambodia OR Indonesia OR Laos OR Myanmar OR

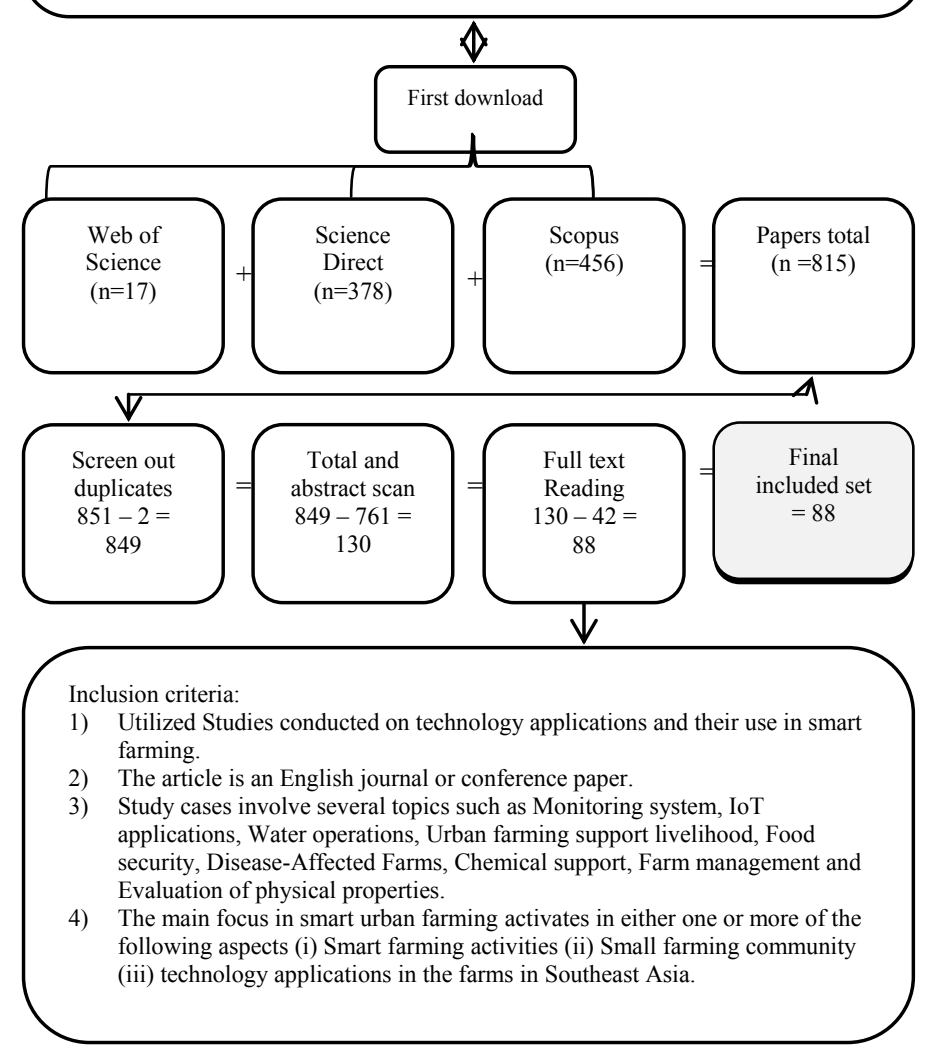

Fig. 1. Flowchart of study selection, including the search query and inclusion criteria

\section{Discussion}


This study provides the latest studies and state-of-the-art urban farming activities in the environment of Southeast Asia. This study aims to highlight the future research trends in this research area. The classification of the study based on the purpose of studies, especially in an emerging field, would provide more benefits. On the one hand, the classification of published works is organised according to different publications. This study helps the researcher to find a general overview of the latest urban farming activities in Southeast Asia. The classification of relevant literature helps to classify these different actions and activities into meaningful, manageable and costeffective planning. To know first possible research trends in this area, mapping on urban farming activities in Southeast Asia in distinct categories highlights the weak and powerful features regarding research coverage.

\subsection{Benefits of urban farming activities}

Studies that provide the discussion on urban farming benefits are immersed. Thus, this section will provide a review of urban farming activities. The development of new technology for agriculture purposes has actively implemented. For example, the use of Electrical Conductivity sensor (ECa) in agriculture provides a huge impact. This technology is fundamental to improve the field management and evaluation of soil chemical, physical properties such as nitrogen $(\mathrm{N})$, exchangeable potassium $(\mathrm{K})$ and available phosphorus $(\mathrm{P})$, and biological parameters, and crop yields. It also helps farmers to manage farms, improve the production costs and reduce environmental degradation by applying the optimal quantity of the required nutrients [18], [23], [15], [16], [11], [10], [24]. This study uses Organic Matter Sensor (SOMSENSE) technology with the integration of software developed using MATLAB based on Red, Green, and Blue (RGB) scales to help the farmers to manage the farm and measure the soil properties. This technology relies on the smart camera, where the farmers will take pictures and then analysed using the laboratory analysis [25]. Another study presents Visible and Near Infrared Reflectance Spectroscopy technology to evaluate the soil properties such as moisture content, bulk density, silt, clay and sand in Malaysian paddy field [19], [14]. Modern agriculture is moving towards the utilisation of robots to inspect crop, check the weather conditions, soil fertility, and soil and crop diseases [17]. Few studies have discussed the utilisation of smart farming technologies. For example, a study has discussed the use of soil saturated hydraulic conductivity (Ks) devices to measure and calculate the irrigation requirement of the water balance equation in the soil farm, and also measure soil physical and chemical properties such as sand, clay and dry bulk density [26]. This study displays technology Microflex$\mathrm{C}$ sensor for measuring evaporation within agricultural crops and crop water requirements inside the farm [25], [27].

\subsection{Challenges of urban farming activities}

Despite numerous benefits acquired from urban farming activities, some challenges and disabilities are facing from this activity that been discussed in past studies. For example, the excessive use of animal fertilizers would affect the properties of the arable soil. It is difficult to see how animal fertilizer is considered a valuable source of crop nutrients. Some fertilizer is not a soil nutrient, and an increase in fertilizer usage has caused damage to agricultural crops [28]. Some fertilizers also contain harmful properties that will lead to many adverse effects on the environment and the characteristics of the soil on the farm and production efficiency as well as on the crop itself [18], [25]. The excessive use of pesticide has led to the failure of pre-harvest agricultural soils in many urban farms in Southeast Asia. Pesticide residues affect consumers' and farmers' health, environmental pollution and limited trading opportunities. The farm's that close to railways, car roads and industrial zones can be contaminated with heavy metals such as lead, sulphur, and nitrate. These toxic materials will be transported to farms and cause a lot of diseases [24]. Some organic waste is harmful and effects on urban agriculture because it may cause crop and vegetable crops to be damaged and render crops inedible [29], [30]. In Southeast Asia some plantations in urban areas use a large proportion of nitrate fertilizers to increase the productivity of vegetables, vegetables and water may contain higher concentrations of nitrates and may cause a serious threat to human health [24].

\subsection{Recommendation of urban farming activities}

Despite the poor management of small farms in many areas of Southeast Asia, few recommendations have been discussed in past studies. For example, it recommended that the local authority to establish close cooperation with the Government to draft protective laws and regulations for open spaces farming. Such cooperation contributes to the success of small farms, for example, climate reporting, waste management, grain, and fertilizer supply and water management. This effort will facilitate the successful uptake of gardening programs [31], encourage small-scale urban agriculture in buildings leading to a sustainable economy [4]. In another study, it also recommended that attention to be given in developing and increasing the spread of small farms, advocacy training and gardening and address issues that could hinder the success of the home gardening inside the urban cites in Philippines. A comprehensive policy is also required for joint management in city authorities as cities become larger, more ethnically diverse and with larger numbers of the population [29].

\section{Limitations}

The limitations of this survey are that, the number and identity of the databases sources that have been highlighted in this research, although we believe that these sources are a reliable and representative collection and cover the subject of wide-ranging research. Second, 
rapid progress in this study determined by a specific time of the survey. Third, we emphasize in this research the limited application of urban agriculture in Southeast Asia research, which happens to be our own goal in this article.

\section{Conclusions}

In this research, all applications of urban agriculture in Southeast Asia countries reviewed all directions. This kind of research continues on this trend. Through deep research in previous studies, we found that there were descriptions and restrictions still vague. The main objective of this study is to highlight the applications of urban agriculture in Southeast Asia for knowledge of developments and discuss in detail the challenges and motivations facing this type of study.

This research partially funded by Universiti Pendidikan Sultan Idris Research Grant (2017-0054-106-61).

\section{References}

1. Leh, O.L.H., et al. Urban farming: Utilisation of infrastructure or utility reserved lands. in Business, Engineering and Industrial Applications (ISBEIA), 2011 IEEE Symposium on. 2011. IEEE.

2. Prasetiyo, W.H., D. Budimansyah, and N. Roslidah, Urban Farming as a Civic Virtue Development in the Environmental Field. International Journal of Environmental and Science Education, 11(10): p. 3139-3146, 2016.

3. Cabalda, A.B., et al., Home gardening is associated with Filipino preschool children's dietary diversity. Journal of the American Dietetic Association 111(5): p. 711-715, 2011.

4. Mintorogo, D.S., W.K. Widigdo, and A. Juniwati, Remarkable 3-in-1 Pakis-Stem Green Roofs for Saving Thermal Flat Rooftop. Advanced Science Letters, 23(7): p. 6173-6178, 2017.

5. Midmore, D.J., and H.G. Jansen, Supplying vegetables to Asian cities: is there a case for periurban production? Food Policy, 28(1): p. 13-27, 2003.

6. Taufani, B., Urban Farming Construction Model on the Vertical Building Envelope to Support the Green Buildings Development in Sleman, Indonesia. Procedia Engineering, 171: p. 258-264, 2017.

7. Chieochan, O., A. Saokaew, and E. Boonchieng. IOT for smart farm: A case study of the Lingzhi mushroom farm at Maejo University. in Computer Science and Software Engineering (JCSSE), 2017 14th International Joint Conference on. 2017. IEEE.

8. Sureephong, P., P. Wiangnak, and S. Wicha. The comparison of soil sensors for integrated creation of IOT-based Wetting front detector (WFD) with an efficient irrigation system to support precision farming. in Digital Arts, Media and Technology (ICDAMT), International Conference on. 2017. IEEE.
9. Yolanda, D., et al. Implementation of real-time fuzzy logic control for NFT-based hydroponic system on Internet of Things environment. in Frontiers of Information Technology (FIT), 2016 International Conference on. 2016. IEEE.

10. Aimrun, W., et al., Spatial variability of bulk soil electrical conductivity in a Malaysian paddy field: key to soil management. Paddy and Water Environment, 5(2): p. 113-121, 2007.

11. Mastura, M., M. Amin, and W. Aimrun, Characterization of paddy soil compaction based on soil apparent electrical conductivity zones. African Journal of Agricultural Research, 6(11): p. 25062515, 2011.

12. Aini, I.N., et al. Auto Guided Oil Palm Planter by using multi-GNSS. in IOP Conference Series: Earth and Environmental Science. 2014. IOP Publishing.

13. Saberioon, M.M., et al., Assessment of colour indices derived from conventional digital camera for determining nitrogen status in rice plants. Journal of Food, Agriculture \& Environment, 11(2): p. 655662, 2013.

14. Gholizade, A., et al., Visible and near infrared reflectance spectroscopy to determine chemical properties of paddy soils. Journal of Food, Agriculture and Environment, 11(2): p. 859-866, 2013.

15. Aimrun, W., M. Amin, and H. Nouri, Paddy field zone characterization using apparent electrical conductivity for rice precision farming. Int. J. Agric. Res, 6: p. 10-28, 2011.

16. Ezrin, M., et al., Relationship between rice yield and apparent electrical conductivity of paddy soils. American Journal of Applied Sciences, 7(1): p. 6370, 2010.

17. Pobkrut, T. and T. Kerdcharoen. Soil sensing survey robots based on electronic nose. in Control, Automation and Systems (ICCAS), 2014 14th International Conference on. 2014. IEEE.

18. Ezrin, M., et al., Development of real time soil nutrient mapping system in paddy field. 2016, Penerbit UTM Press, SKUDAI, JOHOR, 81310, MALAYSIA.

19. Gholizadeh, A., et al., Models for estimating the physical properties of paddy soil using visible and near infrared reflectance spectroscopy. Journal of Applied Spectroscopy, 81(3): p. 534-540, 2014.

20. Saberioon, M.M., et al., A review of optical methods for assessing nitrogen contents during rice growth. Applied engineering in agriculture, 30(4): p. 657-669, 2014.

21. Kassim, M.S.M., et al., Oil Palm Fresh Fruit Bunches (FFB) growth determination system to support harvesting operation. Journal of Food, Agriculture \& Environment, 10(2): p. 620-625, 2012. 
22. Rowshon, M., et al., New performance indicators for rice-based irrigation systems. Paddy and Water Environment, 2006. 4(2): p. 71-79.

23. Gholizadeh, A., et al., Apparent Electrical Conductivity in Correspondence to Soil Chemical Properties and Plant Nutrients in Soil. Communications in soil science and plant analysis, 42(12): p. 1447-1461, 2011.

24. Da Silva Dias, J.C., Guiding strategies for breeding vegetable cultivars. Agricultural Sciences, 5(01): p. 9, 2014

25. Maina, M., et al., Effects of crop evapotranspiration estimation techniques and weather parameters on rice crop water requirement. Australian Journal of Crop Science, 8(4): p. 495, 2014.

26. Aimrun, W. and M. Amin, Pedo-transfer function for saturated hydraulic conductivity of lowland paddy soils. Paddy and Water Environment, 7(3): p. 217-225, 2009.

27. Maina, M., et al., The Water Balance Model and Shallow Water Table Contribution in Irrigated Lowland Rice in the Tanjung Karang Irrigation Scheme in Malaysia. PHILIPPINE AGRICULTURAL SCIENTIST, 97(3): p. 252-256, 2014.

28. Hedlund, A., E. Witter, and B.X. An Assessment of $\mathrm{N}, \mathrm{P}$ and $\mathrm{K}$ management by nutrient balances and flows on peri-urban smallholder farms in southern Vietnam. European Journal of Agronomy, 20(1-2): p. 71-87, 2003.

29. Hubbard, M. and G. Onumah, Improving urban food supply and distribution in developing countries: the role of city authorities. Habitat International, 25(3): p. 431-446, 2001.

30. Moglia, M., Urban agriculture and related water supply: Explorations and discussion. Habitat International, 2014. 42: p. 273-280.

31. Weinberger, K., Home and community gardens in Southeast Asia: potential and opportunities for contributing to nutrition-sensitive food systems. Food security, 5(6): p. 847-856, 2013. 